\title{
Demographic analysis of difficulties related to remote education in Poland from the perspective of adolescents during the COVID-19 pandemic
}

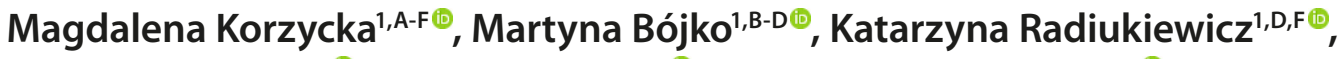 \\ Anna Dzielska, ${ }^{1, A-B, E \oplus}$, Hanna Nałęcz, ${ }^{1, E-F}{ }^{\oplus}$, Dorota Kleszczewska²,A,F ${ }^{2}$, \\ Agnieszka Małkowska-Szkutnik ${ }^{3, A, F}{ }^{\circ}$, Anna Fijałkowska ${ }^{4, A, E-F} \oplus$ \\ ${ }^{1}$ Department of Child and Adolescent Health, Institute of Mother and Child, Warsaw, Poland \\ ${ }^{2}$ Foundation of the Institute of Mother and Child, Warsaw, Poland \\ ${ }^{3}$ Faculty of Education, University of Warsaw, Poland \\ ${ }^{4}$ Department of Cardiology, Institute of Mother and Child, Warsaw, Poland \\ A - Research concept and design, B - Collection and/or assembly of data, C - Data analysis and interpretation, \\ $D$ - Writing the article, $E$ - Critical revision of the article, $F$ - Final approval of article
}

\begin{abstract}
Korzycka M, Bójko M, Radiukiewicz K, Dzielska A, Nałęcz H, Kleszczewska D, Małkowska-Szkutnik A, Fijałkowska A. Demographic analysis of difficulties related to remote education in Poland from the perspective of adolescents during the COVID-19 pandemic. Ann Agric Environ Med. 2021; 28(1): 149-157. doi: 10.26444/aaem/133100
\end{abstract}

\begin{abstract}
I Abstract
Introduction and objective. Due to the COVID-19 pandemic all schools in Poland were closed and obliged to conduct lessons remotely. The aim of the study is to present the demographic analysis of difficulties with remote learning, as perceived by students during coronavirus pandemic in Poland.

Materials and method. In April 2020, a nationwide online survey was conducted among adolescents aged 11-18 ( $N=2408$ ). Quantitative and qualitative data were used. Teenagers were asked about the problems connected with remote learning. In order to examine the overall level of remote learning difficulties, a scale of remote learning difficulties (RLD) was devised (range 0-23 points). Differences connected with gender, age and place of residence were analysed.

Results. More than a half of the teenagers surveyed rated the increased demands from teachers as a major problem. This answer appeared statistically more often among girls than boys (59.6\% v. 53.2\%). Almost every third adolescent saw the lack of consultation (31.6\%) as a significant problem. Difficulties related to learning in the remote system were most often described as considerable by the oldest students (17-18-years-old) and those living in rural areas. The big problem for them was usually much higher requirements of teachers and poor organization of distance learning. The mean level on the scale of remote learning burden was $\mathrm{M}=11.9$ (SD=7.1). Technical difficulties and insufficient skills in using software constituted additional problems most frequently mentioned by students.

Conclusions. There is a need to pay particular attention to organizing appropriate technical conditions for remote learning, especially in rural areas, where students have complained more often than in cities about equipment and problems with access to the Internet during the pandemic.
\end{abstract}

\section{Key words}

adolescents, school, coronavirus, isolation, rural area, pandemic, remote learning.

\section{INTRODUCTION}

On 13 March 2020 in Poland, a state of epidemiological threat was announce and a week later, due to a rapid, although relatively insignificant increase in the number of confirmed SARS-CoV-2 infections, a 'state of epidemic' was declared throughout the country [1]. The COVID-19 pandemic raging worldwide affected the lives of all social groups, regardless of age, gender, and place of residence [2]. To prevent the spread of the virus, public health authorities recommended staying at home and reducing direct contact to a minimum [3].

On 11 March 2020, the authorities decided to close all schools, kindergartens, and nurseries in Poland [4], thus suspending school-based activities. Initially, education and

Address for correspondence: Magdalena Korzycka, Institute of Mother and Child, Department of Child and Adolescent Health, Warsaw, Poland

E-mail: magdalena.korzycka@imid.med.pl

Received: 20.11.2020; accepted: 05.02.2021; first published:05.03.2021 care facilities were closed for a fortnight; however, as the situation evolved, their opening date was delayed. From 25 March onwards, schools were obliged to conduct lessons remotely. Remote learning continued until the end of the school year - 26 June 2020.

While for some adults remote work constituted a challenge requiring them to acquire new skills, for young people, who are skillful at new technologies, the use of remote learning platforms was unlikely to cause any problems $[5,6,7]$. The introduction of remote learning in connection with the COVID-19 epidemic meant that what had previously been a way of spending free time became an obligation, subordinated to new school regulations.

It is therefore justified to raise the question of whether remote teaching can replace direct teaching, or at least partially compensate for the lack of direct meetings with teachers and peers [8]. Remote education and its challenges have become the focus of researchers the worldwide. Surveys 
from different countries show that due to forced restrictions, including physical isolation and school closures, students have experienced emotional problems, feelings of loneliness, uncertainty and anxiety, depression or sleep problems [912]. The functioning of students during isolation, including problems related to remote learning, was also the subject of Polish studies $[13,14]$. It should be remembered that one of the most important factors having a major impact on both the health and quality of life of children and adolescents is social support. School is a place where social relationships are formed, and where young people seek support from their peers, teachers, professional pedagogues, and psychologists $[15,16]$.

The level of education and educational achievements are considered to be social determinants of the health of the population, in addition to the economic level and occupational status [17]. In a time of epidemiological challenge and risk, which increases the important public health problem of social inequalities in health, the issue of education of the young generation becomes more important.

\section{OBJECTIVES}

The main aim of the study is to present demographic analysis of difficulties arising from remote education experienced by young people aged 11-18 in the period 25 March -26 April 2020, during the most severe restrictions related to the COVID-19 pandemic in Poland. The following research questions were devised:

1. What difficulties did young people most often see as a major problem during the period of the initial weeks of the pandemic, when tight restrictions were in force?

2. How did the ranking of these problems relate to gender, age, and place of residence?

3. What was the overall level of remote learning difficulties in the investigated sample, as measured by the Remote Learning Difficulties (RLD) scale?

4. In what way does the overall level of difficulty connected with remote learning depend on gender, age, and place of residence of the surveyed adolescents?

5. What additional problems do young people mention regarding remote learning?

\section{MATERIAL AND METHODS}

Organisation of the study and participants examined. A nationwide survey on the functioning of young people during self-isolation in the initial period of the pandemic was conducted between 13-26 April 2020. This was a web-based cross-sectional study of a sample of a 2,408 adolescents aged 11-18. Recruitment was conducted with a convenient, nonprobabilistic procedure according to the inclusion criteria of age (11-18 years). The coordinating centre of the 'Youth and COVID-19' survey was the Institute of Mother and Child (Instytut Matki i Dziecka, IMiD), with the support of the IMiD Foundation (FIMiD) in Warsaw and the Faculty of Education at Warsaw University.

The study participants were recruited by placing invitations on the IMiD and FIMiD social media platforms, as well as sending invitations to schools selected by school nurses in each province and to the schools cooperating with the IMiD. The Bioethics Committee cooperating with the Institute of
Mother and Child issued a positive opinion (Opinion No. $24 / 2020$ ) on the adherence to ethical principles of the survey entitled 'Youth and COVID-19' carried out online at home. 3,351 completed questionnaires were returned for analysis.

After completing the process of data cleaning, a final sample of 2,408 teenagers (girls constituted $60.1 \%$ of the total) was obtained. Detailed characteristics of the sample are presented in Table 1.

Research tools and indicators. The online questionnaire contained author's questions referring to basic demographic data (age, gender, place of residence, school grade), a category of questions concerning the implementation of health promotion in the environment of children and adolescents (the guidelines were used in the implementation of a nationwide education and information campaign for children and adolescents), and categories of questions enabling the assessment of five areas related to the functioning of students in self-isolation. The following were used in the described analyses: demographic variables and a category of questions on the experiences of young people connected with remote learning in the studied period (eight questions) as well as answers to descriptive questions.

Demographic variables. The analyses included questions on gender, age, and place of residence. The age of the respondents was analysed in three categories: 11-12, 13-16 and 17-18. Basing on preliminary analyses, it was concluded that in terms of the variables selected for the purpose of assessing remote learning difficulties, the two outermost age groups (11-12 and 17-18 years) may differ considerably from the others. Therefore, to investigate noteworthy, age-dependent differences, the decision was made to conduct the analyses in three categories.

The question regarding the place of residence (Where do you live?) had the following categories of answers: in the countryside; in a small town (up to 20,000 inhabitants); in a larger town (between 20,000-100,000 inhabitants); in a big city (over 100,000 inhabitants). For the purpose of this study, after combining the second and the third categories, this variable was analysed in three groups:

- rural area;

- small or medium town (up to 100,000 inhabitants);

- big city (over 100,000 inhabitants).

Problems related to learning. The investigated adolescents answered the question: In your opinion, how serious a problem are the following situations connected with school obligations at this time? on the basis of the eight statements concerning learning problems during the pandemic, including the conditions for online learning and the organisation of remote learning. These are discussed in detail in the Results section of this study.

The young people surveyed were asked to assess each of the statements on a scale from 1 (not a problem at all) to 5 (a very big problem). The variables were analysed in three categories: lack of problem (1-2); medium problem (3); significant problem (4-5). To improve readability, in the Results and in the Tables only two extreme categorie 'lack of problem' and 'significant problem' were described and shown.

The scale of remote learning difficulties. To examine the general level of problems experienced by young people 
Table 1. Sample characteristics

\begin{tabular}{lll}
\hline & $\mathbf{N}$ & $\%$ \\
\hline Gender (N=2408) & & \\
\hline Boys & 961 & 39.9 \\
\hline Girls & 1447 & 60.1 \\
\hline Age (N=2408) & & \\
\hline $11-12$ & 736 & 30.6 \\
\hline $13-14$ & 671 & 27.9 \\
\hline $15-16$ & 593 & 24.6 \\
\hline $17-18$ & 408 & 16.9 \\
\hline Place of residence (N=2406) & & \\
\hline Rural area & 670 & 27.8 \\
\hline Small town (to 20,000 inhabitants) & 503 & 20.9 \\
\hline Medium town (20,000-100,000 inhabitants) & 920 & 38.2 \\
\hline Big city (over 100,000 inhabitants) & 313 & 13.0 \\
\hline
\end{tabular}

in connection with remote education, a scale of Remote Learning Difficulties (RLD) was devised. The answers to the questions were scored from 0 to 4 . The overall index of the scale equaled $0-32$ points. Higher scores mirrored an escalation of the problems arising from remote learning, according to young people.

The particular statements making up the RLD general index revealed, respectively, high correlations with the overall score of the whole scale, ranging from $0.440-0.633$. The studied dimension regarding difficulties with learning constituted one factor and accounted for $43 \%$ of the total scale variation. High reliability of the scale was also demonstrated, as the Cronbach's alpha-Cronbach coefficient amounted to $\alpha=0.81$ and did not increase when removing individual statements included in the scale.

Descriptive question. The question on the difficulties connected with remote education was supplemented with a category labeled 'Other...' ' The aim was to obtain additional, in-depth information about the problems that young people face in connection with remote learning. A total of 152 teenagers, more than two-thirds of whom were girls, shared their additional opinions on this topic.

For this study, all additional statements made by young people concerning remote learning were organised and objectified according to the methodology of qualitative content analysis $[18,19]$. They were categorised in terms of their content - with the key categories being separated and subjected to qualitative and quantitative analysis. The analysis included only those statements that were related to remote learning. After analysing all the answers to the open question, they were divided into two groups - the first group consisted of the answers that the participants could choose from in the closed categories $(\mathrm{N}=96)$, the second group consisted of the answers $(\mathrm{N}=56)$ not included in the category of closed questions. On this basis, five additional subject areas were identified and discussed in the results section.

Statistical analyses. Quantitative and qualitative data were analysed using a mixed method approach [20]. The relationship between each of the evaluated eight areas of remote learning difficulties and gender, age and place of residence was studied using the chi-square test. Descriptive statistics regarding the level of burdening young people with difficulties connected with remote learning based on the RLD scale were presented: mean values and standard deviations. Due to the different distribution of the RLD scale, compared to a typical distribution, the MannWhitney's U test for independent samples was used to compare the mean RLD values with regards to gender. The non-parametric Kruskal-Wallis test was used to compare the mean RLD values depending on age and place of residence. The significance level $\mathrm{p}<0.05$ was assumed in the study. Analyses were carried out with the use of IBM SPSS Statistics v. 25 software.

The additional remote learning problems mentioned by young people were analysed qualitatively.

\section{RESULTS}

Ranking of remote learning difficulties as assessed by young people. The full distribution of responses to the eight statements on remote learning difficulties by two categories mirroring the severity of the problem in the total group and depending on gender and age is shown in Table 2.

For most of the examined adolescents (57.1\%), the increased requirements imposed by teachers, compared to those they had previously experienced in school-based education, constituted a significant problem with remote education. For almost every third teenager, big obstacles during the pandemic period were the lack of possibility to consult the teacher in case of problems with understanding the material (31.6\%), and poor organisation of remote learning at school (29.8\%). More than $1 / 4$ of the teenagers perceived the difficulties in obtaining feedback from the teacher $(27.3 \%)$ on their learning progress as a significant problem, and $1 / 5$ of them were unable to compare their own achievements with those of their class mates (20.8\%). It is worth noting that only $12.7 \%$ of students complained about the lack of support from parents in school matters. Similarly, in the total group, only a small number of students assessed the difficulties related to the conditions for online learning or access to educational materials as a significant problem.

Girls were significantly more likely than boys to perceive the increased requirements at school as a big problem $(59.6 \%$ vs. $53.2 \%$; $=0.001)$. There were no statistically significant gender-specific differences in the responses to the other seven analysed areas concerning remote learning during the pandemic.

The most statistically significant differences in the assessment of problems regarding remote learning were observed with reference to the age of the investigated youth. Table 2 presents a full distribution into particular statements from the educational category in particular age groups.

Big difficulties related to school learning in the remote system were most often reported by the oldest students (17-18-years-old). The most significant problem concerned much higher requirements imposed by teachers comparing to school-based education $(\mathrm{p}<0.001)$. For nearly $2 / 3$ of pupils aged 17-18 this was a great difficulty. They also reported -significantly more often than their younger colleagues difficulty resulting from poor organisation of remote learning $(\mathrm{p}<0.001)$, lack of possibility to consult $(\mathrm{p}=0.005)$, and difficulty in obtaining feedback from the teacher $(\mathrm{p}<0.001)$. 
These situations constituted a significant problem for nearly $1 / 3$ of the students at that age. Every fourth adolescent aged 17-18 (24.5\%) experienced big difficulties with access to didactic materials significantly more often than younger students $(\mathrm{p}<0.001)$. In most cases, the youngest students (11-12-years-old) complained the least about the difficulties arising from remote learning. More than half of the young people from this group did not see the situations connected with remote learning as a significant problem. The area which was the most problematic for them, in comparison with older students, was the lack of possibility to compare their progress with their peers $(p<0.001)$. On the other hand, this issue was reported a little less frequently by the oldest students, and the least frequently by teenagers aged 13-16 years.

Taking into consideration the place of residence, the percentage of students who negatively assessed school requirements in the new educational reality was the highest among the students living in rural areas, and decreased with the growth of the size of the town or city where the adolescents lived $(\mathrm{p}<0.01)$ (Tab. 3). Noteworthy differences related to the place of residence were also observed in the case of assessing the possibility of comparing progress and achievements with peers $(p=0.005)$. The lack of such a possibility was most often perceived as a significant problem by the young people from small and medium towns (22.7\%), and the least often by the students from large cities (15.0\%). Teenagers living in rural areas more often than young people from towns and cities complained about the lack of proper conditions for online learning (statistical trend: $\mathrm{p}=0.056$ ). Preparing the right conditions for remote learning constituted a substantial challenge for $36 \%$ of the teenagers living in rural areas and $26 \%$ of the adolescents from large cities.

General level of burden with remote learning difficulties. On the scale of remote learning (0-32 points) in the whole surveyed group of young people, the mean level equaled $\mathrm{M}=11.9$ ( $\mathrm{SD}=7.1$ ). Analysis with the use of non-parametric tests revealed that girls had a higher mean level of remote learning burden than boys; however, this was not a statistically significant correlation $(\mathrm{p}=0.274)$ (Tab. 4). Nevertheless, it was found that the mean level of burden with problems arising from remote learning was considerably diversified with respect to the age of the investigated adolescents $(\mathrm{p}<0.001)$ and their place of residence $(\mathrm{p}=0.020)$. The oldest adolescents $(\mathrm{M}=13.71 ; \mathrm{SD}=7.07)$ and adolescents living in rural areas $(\mathrm{M}=12.26, \mathrm{SD}=7.28)$ experienced the greatest difficulties with remote learning. The least burdened were the students from the age group 11-12 $(\mathrm{M}=11.21 ; \mathrm{SD}=7.32)$ and those from large cities $(\mathrm{M}=10.85 ; \mathrm{SD}=7.09)$.

Additional difficulties related to online learning during the Covid-19 epidemic. Areas that did not appear in the closed categories of questions but were indicated by students $(\mathrm{N}=56)$ in response to the open question were as follows:

1. Technical problems and insufficient knowledge and skills related to the operation of computer hardware and software

Table 2. Ranking of problems with remote learning total, by gender and age (\%)

\begin{tabular}{|c|c|c|c|c|c|c|c|c|}
\hline \multirow{2}{*}{ Level of the problem } & \multirow{2}{*}{ Total } & \multicolumn{2}{|c|}{ Gender } & \multirow{2}{*}{$X^{2}\left(p^{\wedge}\right)$} & \multicolumn{3}{|c|}{ Age } & \multirow{2}{*}{$x^{2}\left(p^{\wedge}\right)$} \\
\hline & & Boys & Girls & & $11-12$ & $13-16$ & $17-18$ & \\
\hline \multicolumn{9}{|c|}{ Increased requirements imposed by teachers } \\
\hline Lack of problem & 25.1 & 29.3 & 22.4 & \multirow{2}{*}{$\begin{array}{c}13.14 \\
(0.001)\end{array}$} & 31.2 & 23.9 & 17.8 & \multirow{2}{*}{$\begin{array}{c}23.79 \\
(<0.001)\end{array}$} \\
\hline Significant problem & 57.1 & 53.2 & 59.6 & & 52.0 & 58.4 & 62.1 & \\
\hline \multicolumn{9}{|c|}{ The lack of possibility to consult the teacher in case of problems with understanding the material } \\
\hline Significant problem & 31.6 & 30.6 & 32.2 & $\begin{array}{c}1.36 \\
(0.505)\end{array}$ & 30.5 & 31.0 & 35.2 & $\begin{array}{c}14.73 \\
(0.005)\end{array}$ \\
\hline \multicolumn{9}{|c|}{ Poor organisation of remote learning at school } \\
\hline Lack of problem & 46.8 & 46.7 & 46.8 & \multirow{2}{*}{$\begin{array}{c}0.10 \\
(0.947)\end{array}$} & 53.1 & 46.3 & 37.0 & \multirow{2}{*}{$\begin{array}{c}33.07 \\
(<0.001)\end{array}$} \\
\hline Significant problem & 29.8 & 30.2 & 29.6 & & 23.1 & 30.6 & 39.3 & \\
\hline \multicolumn{9}{|c|}{ Difficulties in obtaining feedback from the teacher } \\
\hline Significant problem & 27.3 & 26.5 & 27.8 & $\begin{array}{c}3.86 \\
(0.145)\end{array}$ & 23.2 & 27.0 & 35.5 & $\begin{array}{c}22.31 \\
(<0.001)\end{array}$ \\
\hline \multicolumn{9}{|c|}{ Lack of possibility to compare their own achievements with those of their classmates } \\
\hline Lack of problem & 63.0 & 61.7 & 63.8 & \multirow{2}{*}{$\begin{array}{c}2.19 \\
(0.334)\end{array}$} & 57.2 & 66.8 & 61.3 & \multirow{2}{*}{$\begin{array}{c}20.01 \\
(<0.001)\end{array}$} \\
\hline Significant problem & 20.8 & 22.4 & 19.8 & & 24.7 & 17.6 & 23.9 & \\
\hline \multicolumn{9}{|c|}{ Lack of access to educational materials } \\
\hline Lack of problem & 61.7 & 61.7 & 61.6 & \multirow{2}{*}{$\begin{array}{c}0.07 \\
(0.963) \\
\end{array}$} & 66.6 & 61.8 & 52.1 & \multirow{2}{*}{$\begin{array}{c}24.24 \\
(<0,001)\end{array}$} \\
\hline Significant problem & 17.9 & 18.1 & 17.8 & & 16.6 & 16.6 & 24.5 & \\
\hline \multicolumn{9}{|c|}{ Lack of conditions for online learning } \\
\hline Lack of problem & 67.6 & 68.3 & 67.2 & \multirow{2}{*}{$\begin{array}{c}1.93 \\
(0.381)\end{array}$} & 69.0 & 68.8 & 61.3 & \multirow{2}{*}{$\begin{array}{c}8.77 \\
(0.067)\end{array}$} \\
\hline Significant problem & 16.4 & 17.1 & 16.0 & & 15.0 & 16.4 & 19.2 & \\
\hline \multicolumn{9}{|c|}{ Lack of support from parents in school activities } \\
\hline Lack of problem & 75.4 & 76.6 & 74.7 & $\begin{array}{c}1.22 \\
(0.541)\end{array}$ & 76.5 & 76.5 & 70.1 & $\begin{array}{c}8.35 \\
(0.079)\end{array}$ \\
\hline
\end{tabular}

$\mathrm{p}^{\wedge}$ - significance level $\mathrm{p}<0.05$ 
Table 3. Ranking of problems with remote learning by place of residence (\%)

\begin{tabular}{|c|c|c|c|c|}
\hline \multirow[b]{2}{*}{ Level of the problem } & \multicolumn{3}{|c|}{ Place of residence } & \multirow[b]{2}{*}{$x^{2}\left(p^{\wedge}\right)$} \\
\hline & $\begin{array}{c}\text { Rural area } \\
\mathrm{N}=670\end{array}$ & $\begin{array}{l}\text { Small and medium town } \\
\qquad \mathrm{N}=1423\end{array}$ & $\begin{array}{l}\text { Big city } \\
N=313\end{array}$ & \\
\hline Lack of problem & 24.7 & 23.9 & 30.8 & \multirow{2}{*}{$\begin{array}{c}18.79 \\
(0.001)\end{array}$} \\
\hline Significant problem & 60.8 & 57.8 & 46.5 & \\
\hline Lack of problem & 47.0 & 48.1 & 53.1 & \multirow{2}{*}{$\begin{array}{c}2.98 \\
(0.561)\end{array}$} \\
\hline Significant problem & 32.5 & 31.7 & 29.3 & \\
\hline \multicolumn{5}{|c|}{ Poor organisation of remote learning at school } \\
\hline Lack of problem & 48.1 & 46.5 & 44.7 & \multirow{2}{*}{$\begin{array}{c}1.52 \\
(0.822)\end{array}$} \\
\hline Significant problem & 29.5 & 29.5 & 32.2 & \\
\hline \multicolumn{5}{|c|}{ Difficulties in obtaining feedback from the teacher } \\
\hline Lack of problem & 48.7 & 52.2 & 58.2 & \multirow{2}{*}{$\begin{array}{c}7.20 \\
(0.125)\end{array}$} \\
\hline Significant problem & 28.8 & 27.1 & 24.9 & \\
\hline \multicolumn{5}{|c|}{ Lack of possibility to compare their own achievements with those of their classmates } \\
\hline Lack of problem & 65.8 & 60.3 & 69.2 & \multirow{2}{*}{$\begin{array}{r}12.09 \\
(0.017)\end{array}$} \\
\hline Significant problem & 19.6 & 22.7 & 15.0 & \\
\hline \multicolumn{5}{|c|}{ Lack of access to educational materials } \\
\hline Lack of problem & 59.5 & 62.2 & 64.0 & \multirow{2}{*}{$\begin{array}{c}2.22 \\
(0.695)\end{array}$} \\
\hline Significant problem & 19.5 & 17.4 & 16.5 & \\
\hline \multicolumn{5}{|c|}{ Lack of conditions for online learning } \\
\hline Lack of problem & 64.0 & 67.8 & 74.4 & \multirow{2}{*}{$\begin{array}{c}9.22 \\
(0.056)\end{array}$} \\
\hline Significant problem & 18.4 & 16.2 & 13.2 & \\
\hline \multicolumn{5}{|c|}{ Lack of support from parents in school activities } \\
\hline Significant problem & 13.7 & 12.3 & 12.5 & $\begin{array}{c}2.90 \\
(0.574)\end{array}$ \\
\hline
\end{tabular}

$\mathrm{p}^{\wedge}$ - significance level $\mathrm{p}<0.05$

for remote learning $(\mathrm{N}=22)$. The students had a problem with the Internet, they wrote that in online lessons everything jammed, and that there was a problem with sending tasks (I cannot send photos). According to the students, the problem is that not everybody can do the tasks on the computer and there is a weak Internet connection in the case of those living in the countryside. There were also negative evaluations of the Internet platforms and applications that were used for online lessons: weak communication platforms (the whole class cannot talk at once). Girls, more often than boys, mentioned technical problems and lack of sufficient knowledge or skills to operate the computer.

2. Lack of school activities, including sports, and school atmosphere (personal contact with teachers and peers) $(\mathrm{N}=13)$. The young people complained about the lack of school atmosphere motivating them to act and think. They also pointed to the lack of direct contact with peers, the problem being the lack of possibility to talk to colleagues during breaks and the lack of a colleague sitting at the same table. Students also regarded the lack of direct contact with teachers as a difficulty: lack of teachers (e.g. we always meet teachers at school, and now via the Internet). The boys also complained about the lack of PE and football.

3. No motivation to learn online. During remote learning in the time of pandemic, teenagers also lacked sufficient motivation to learn (9 answers, 7 of which were given by girls): I just lack motivation? I don't know, it's different for
Table 4. General level of problems with remote learning by gender, age, and place of residence

\begin{tabular}{|c|c|c|}
\hline & $\begin{array}{l}\text { Mean } \\
(\text { SD) }\end{array}$ & $\begin{array}{l}\text { Value } \\
(p)^{b}\end{array}$ \\
\hline Total & $11.91(7.19)$ & \\
\hline Boys & $12.02(7.12)$ & \multirow{2}{*}{$\begin{array}{l}492366.000^{\circ} \\
(0.274)\end{array}$} \\
\hline Girls & $11.73(7.28)$ & \\
\hline \multicolumn{3}{|l|}{ Age (years) } \\
\hline $11-12$ & $11.21(7.32)$ & \multirow{3}{*}{$\begin{array}{l}31.353^{d} \\
(<0.001)\end{array}$} \\
\hline $13-16$ & $11.74(7.06)$ & \\
\hline $17-18$ & $13.71(7.07)$ & \\
\hline \multicolumn{3}{|l|}{ Place of residence } \\
\hline Rural area & $12.26(7.28)$ & \multirow{3}{*}{$\begin{array}{l}7.820^{d} \\
(0.020)\end{array}$} \\
\hline $\begin{array}{l}\text { Small and medium town } \\
\text { (up to } 100,000 \text { inhabitants) }\end{array}$ & $11.99(7.14)$ & \\
\hline $\begin{array}{l}\text { Big city } \\
\text { (over 100,000 inhabitants) }\end{array}$ & 10.85 (7.09) & \\
\hline
\end{tabular}

a SD - standard devation; ${ }^{\mathrm{b}}$ significance level $\mathrm{p}<0.05$

'U-Mann Whitney's test

dKruskal-Wallis's test

me to write tests knowing that I could just download all the answers, and nobody would know. While learning at home, some of the young people lost their enthusiasm for learning and wrote about their lack of motivation and willingness 
to learn. According to the teenagers, teachers do not check their learning progress, resulting in a lack of motivation.

4. Lack of precise criteria for evaluation and no possibility to improve the grades. Girls were the only ones to complain about these problems $(\mathrm{N}=5)$. They wrote that the problem is the lack of information on, e.g., how to improve grades. Teachers ask for homework, make us send it, I spend all day doing the homework, send it to them, and they don't give me my grade, I think they don't check the homework, they just check if somebody sent them, and if not, they give them a bad mark ('1') with no chance for improvement.

5. No precise timetable $(\mathrm{N}=2)$. Students noticed a difficulty due to the lack of a clearly detailed online school timetable: My colleague has an online 'timetable' given by the school (...) Mine is so 'scattered' - it is not organised.

\section{DISCUSSION}

The closure of schools caused by the coronavirus pandemic and the running of remote education has become a challenge for everyone involved, from the pupils themselves to their parents and teachers, to the institutions involved in the organization of education. Students in Poland have never before used online education instead of traditional school education on such a scale.

The research carried out by the team at the Department of Child and Adolescent Health and the IMiD Foundation reveals that young people perceived excessive demands from teachers and curricular overburdening of students as the most significant problem related to remote learning. Similar admissions were made by the students participating in the 'Action Navigation' survey conducted by Grzelak et al. at the Integrated Prevention Institute. In this survey, young people point out that the greatest challenge related to learning via the Internet is not so much the lack of appropriate equipment or Internet connection, but the curricular overburdening [13]. It is worth mentioning that in a study conducted by the Digital Centre, in which teachers indicated problems related to remote learning, it was also the burden related to the time-consuming nature of the whole remote learning process that was most frequently chosen [21].

One of the reasons for the overburdening that the young people indicated may be the very form of online learning. Remote learning is based on presenting and processing many visual stimuli and numerous methods of response (including text, audiovisual graphics, and animation). This forces the digital learner to be multi-tasking and can result in overloading the memory and reduced ability to accurately absorb, process and memorize information. The students themselves also point out that remote lessons are less attractive than those taught at school [22]. It seems necessary to ensure that the time spent by students in front of the computer screen and other digital devices, especially when remote learning is a necessity, is reasonably regulated. As Polish studies indicate, during the period of the epidemic, excluding school duties, the time spent online on entertainment, including watching movies and playing games, has increased and some students, parents and teachers have had clear symptoms misuse of digital media [23]. A large group of students often used social networking websites during online activities, played games, browsed the Internet for private purposes, wrote to someone without any connection to the lessons, or used their smartphons for non-learning purposes [23]. Therefore, it is reasonable to include in future research information on how much time students spend in front of the screen during and outside school activities, and to examine and estimate the overall screen time. It is worth taking into account the recommendations on the maximum time that children can spend in front of the computer at one time, and bear them in mind when planning lessons [24]. These guidelines should be adapted to the age of the students and include a daily and weekly schedule and type of the lessons [23].

A study by the Institute of Mother and Child revealed that girls were considerably more likely than boys to perceive excessive demands from teachers as a major problem. This was the only difficulty that was significantly varied in terms of gender. Garza and Jovanovic demonstrated that girls were less resistant to stressful situations than boys, which may account for the differences observed [25]. In contrast, the HBSC study of 2018 showed that experiencing school stress is - among others - gender-specific. Girls were found to be much more likely to experience high levels of school stress compared to boys, which may partly explicate the data obtained in the presented study [26].

The unprecedented situation related to the pandemic caused youths to feel increased anxiety, depression and stress $[23,27,28]$. In order for the learning process to proceed properly, students need a sense of physical and mental health and safety. Children learn best when their environment is friendly and 'safe' and when teachers respond to their strengths and needs, but fear and anxiety weaken cognitive abilities and cause learning disruption [29].

Another serious problem often indicated by the young people surveyed, was the poor organisation of remote learning and the lack of possibility to discuss and clarify difficult topics. For some of the respondents, the lack of feedback from teachers and lower motivation to learn were also very problematic, as they pointed out in their descriptive answers to the open question. Adolescents lacked direct contact with teachers and the possibility to discuss with them the problems they encounter at school. According to research on the environment in which online education takes place, the effectiveness of learning depends not only on the individual characteristics of a student and his/her surrounding, but also on the speed and quality of the teacher's feedback [30].

Another problem highlighted by young people in this study in the descriptive answers, regardless of gender, was the feeling of isolation and loneliness, which is also supported by other studies. Young people complain about the lack of direct relationships with their peers. This is undoubtedly influenced by the developmental period of this age group. Adolescents have a much greater need to interact with their peers than adults [31]. Isolation and radical restrictions on adolescents' ability to establish direct social contacts outside the home can have lasting negative consequences for their physical and mental health [32].

As many as $2 / 3$ of the investigated teenagers did not complain about the conditions for remote learning. Notably, more often problems related to the Internet connection or equipment were observed by the young people living in rural areas. Such issues were mentioned by the young people when answering the open question and were more often indicated by girls and students under 17 years of age than the rest of the respondents. Other studies conducted among students from 
Kraków also indicated that equipment problems were more often reported by younger students, who require parental assistance to take part in an online lesson [14].

Studies demonstrate that young people, despite rather favourable conditions, find it difficult to adapt to the remote learning system, and signal many problems related to it [14, 22]. The 17-18-year-olds investigated for the current study, more often than younger students, pointed to the analysed problems with remote learning. For older adolescents (including those preparing for their end-of-school exam - 'matura exam'), more often than for other age groups, the (subjectively assessed) low quality of remote education, hindered access to didactic materials and limited contact with teacher, constituted a considerable problem. Their assessment may have been influenced by the fear of failure during the enrollment in tertiary schools process due to the switch to remote education, which some respondents mentioned in their answer to the open question. Changes and uncertainties related to the pandemic could affect their educational decisions and prospects. Similar conclusions were reached by Długosz, who conducted a survey among youth in Kraków [14]. About challenges related to the future, feeling uncertain about the future plans, e.g. the college transition, summer plans or college applications were also reported by adolescents in a qualitative study conducted in the USA [33].

However, there are also voices indicating that older teenagers appreciate this education system. In the study by A. Jurczak, the author reports that students of grades VII and VIII of primary schools and students of secondary schools indicated that remote learning allows them to save time and focus on examination subjects [34].

The research presented in this article carried out by the Institute of Mother and Child demonstrates that the youngest students (11-12-years-of-age) complained the least frequently about remote learning, although they also noticed the disadvantages of this system, especially the lack of possibility to compare progress with their peers. Differences in the assessment of problems and the quality of remote learning may result from the education stage of the students. Young people, who had uncertain perspectives due to the lack of clear information about the exams and the general further education pathway, might have evaluated more rigorously the actions undertaken by schools and educational decisions taken at national level [8].

Excessive control of parents, caused in the initial period of the pandemic by the ban on leaving home without a guardian until the age of 18, and learning at home, could also have had an impact. Nearly $13 \%$ of the students felt that during the pandemic their relationship with their parents/guardians had become difficult [23]. Young people also lacked access to libraries, school teaching materials and direct advice from teachers. On the other hand, younger students, most of whom received help from their parents and spent more time with them than before the pandemic, were better off learning at home. The youngest lacked the most face-to-face interaction with their peers [35]. Half of the students indicated during lockdown, that before the pandemic, relationships with colleagues from their class were better [23].

This study analysed the problems connected with remote learning in terms not only of the gender and age of the respondents, but also of their place of residence. The place of residence is important with a view to assessing the conditions for remote learning. The young people living in rural areas complained more often about the lack of conditions for remote learning than the young people from cities. Indeed, rural residents were also much more likely to pay attention to the much greater demands imposed by teachers than in traditional school teaching. International analyses indicate differences in educational opportunities between students from urban and rural areas. The results of the OECD's Programme for International Student Assessment (PISA), showed that students in large cities scored 31 points higher, on average, in science than their peers from rural regions [36]. This is important for individuals, for their future and prosperity, including material prosperity, as well as for regional economic efficiency and innovation, to ensure high quality education also in rural areas. Despite the fact that in recent years in Poland the differences in development between the rural and urban areas have been decreasing, including in the fields of infrastructure or household equipment and the income of the agricultural and rural population increased, there are still the differences in the economic situation [37, 38]. In view of this, the place of residence can be treated in this case as one of the factors related to the level of economic status. As research indicates, territorial diversity as well as the socio-economic situation of students' families are important elements influencing educational inequalities [36, 39]. For example, children from wealthier families spend $30 \%$ more time studying at home than those from poorer families [23]. It should also be emphasized that due to the remote learning, the students' families faced additional financial challenges. As shown by the results of Polish research, for the purposes of remote education every fifth student needed to purchase computer hardware and additional Internet data transfer, as well as appropriate software [23]. Due to remote learning in the USA, families with lower incomes were more exposed to financial burdens than families with higher incomes, and $12 \%$ of families also reported the need to buy a better Internet subscription [40]. These economic challenges related to the organization of remote learning concerned both the families of the students and were present also on the school and community levels.

Therefore, during the pandemic the place of residence of the students became more important in the context of educational process, as it could differentiate, among other things, access to the Internet and other resources enabling participation in online classes. Taking into account the socio-economic factors influencing the functioning and school achievements of students, in future research, it is recommended to inclu, in addition to the place of residence, the financial situation of the family, as well the material resources of the school (including school equipment) and factors on the regional level (e.g. cooperation of schools with local government, social and cultural resources, organization of after-school time).

The issue of remote learning is still relevant, even though with the start of the new school year 2020/2021 schools were reopened and school-based education returned. In accordance with the Regulation of the Ministry of National Education of 12 August 2020 [41], in the event of a worsening of the epidemiological situation, a mixed (or hybrid) education model was considered, including distance learning for a group of or for all students.

Due to the dynamic growth of the number of infected individuals during the pandemic, in mid-October it was 
decided to change the functioning of schools and return to remote learning for secondary school students [42] and students from the higher grades of primary schools [43]. From 9 November 2020, distance learning was applied once again to the entire population of students in Poland.

The main limitation of the current study is that the questions in the online survey were answered by youths who volunteered, therefore the study was not conducted on a representative sample. On the other hand, undertaking an in-depth demographic analysis, including the study of differences by age and by place of residence, is unique at this point. Another advantage of the survey was the obtaining of additional opinions from students, and the inclusion of qualitative analyses.

\section{CONCLUSIONS}

1. The big difficulties arising from remote learning during the pandemic were most often noted by the oldest students (17-18-years-old) and those living in rural areas. Therefore, it is worth paying special attention to this group when planning further in-depth research.

2. There is a need to pay particular attention to organising appropriate technical conditions for remote learning, especially in rural areas, where young people have complained more often than in cities about equipment and Internet access problems during the pandemic.

3. Due to the epidemiological situation, it is important to implement targeted funding for students and regions with the greatest needs, also taking into account remote education.

\section{Acknowledgement}

Realization of the study entitled 'Youth and COVID-19' was supported by resources of the Foundation of the Institute of Mother and Child in Warsaw, Poland

\section{REFERENCES}

1. The Decree of the Minister of Health on 20 March 2020 declaring the state of epidemic on the territory of the Republic of Poland. Act of 2020, Pub. L. No. 491. https://dziennikustaw.gov.pl/DU/2020/491. (access: 2020.10.09).

2. Prime $\mathrm{H}$, Wade $\mathrm{M}$, Browne DT. Risk and resilience in family well-being during the COVID-19 pandemic. Am Psychol. 2020; 75(5): 631-643. http://dx.doi.org/10.1037/amp0000660

3. Prem K, Liu Y, Russell TW, et al. The effect of control strategies to reduce social mixing on outcomes of the COVID-19 epidemic in Wuhan, China: a modelling study. Lancet Public Health. 2020; 5(5): 261-270. https://doi.org/10.1016/S2468-2667(20)30073-6

4. The Decree of the Minister of National Education on 11 March 2020 on the temporary limitation of the functioning of the education system units in relation to the prevention, counteraction and combating COVID-19. Act of 2020, Pub. L. No. 410. https://isap.sejm.gov.pl/isap. nsf/DocDetails.xsp?id=WDU20200000410 (access: 2020.12 .29 ).

5. Raišienė AG, Rapuano V, Varkulevičiūtè K, et al. Working from Home-Who Is Happy? A Survey of Lithuania's Employees during the COVID-19 Quarantine Period. Sustainability. 2020; 12(13): 5332. https://doi.org/10.3390/su12135332

6. Uhls YT, Ellison NB, Subrahmanyam K. Benefits and Costs of Social Media in Adolescence. Pediatrics. 2017; 140(2): 67-70. https://doi. org/10.1542/peds.2016-1758E

7. Woynarowska B. Sedentary behaviour in front of the screen during leisure. In: Mazur J, Małkowska-Szkutnik A, editors. Students' health in 2018 against the backdrop of the new HBSC research model. Inst. of Mother and Child, Warsaw; 2018. p. 93-102.
8. Lee J. Mental health effects of school closures during COVID-19. Lancet Child Adolesc Health. 2020; 4(6): 421. https://doi.org/10.1016/ S2352-4642(20)30109-7

9. Mental health considerations for children \& adolescents in COVID-19 Pandemic. Imran N, Zeshan M, Pervaiz Z. Pak J Med Sci. 2020; 36(COVID19-S4): S67-S72. https://doi.org/10.12669/pjms.36. COVID19-S4.2759

10. Jiao WY, Wang LN, Liu J, et al. Behavioral and Emotional Disorders in Children during the COVID-19 Epidemic. J Pediatr. 2020; 221: 264-266. el. https://doi.org/10.1016/j.jpeds.2020.03.013

11. Richardson C, Oar E, Fardouly J, Magson N, Johnco C, Forbes MR.The Moderating Role of Sleep in the Relationship Between Social Isolation and Internalising Problems in Early Adolescence. Rapee Child Psychiatry Human Develop. 2019; (50): 1011-1020.

12. Singh S, Roy D, Sinha K, et al. Impact of COVID-19 and lockdown on mental health of children and adolescents: A narrative review with recommendations. Psychiatry Res. 2020; 293: 113429. https://doi. org/10.1016/j.psychres.2020.113429

13. Youth during the epidemic. Results of the survey: NAVIGATION ACTION - protect yourself, support others. Institute of Integrated Prevention. Foundation, Warsaw; 2020. http://edukacja.gdynia. pl/wpcontent/uploads/2020/05/RAPORT_Mlodziez_w_czasie_ epidemii_2020_IPZIN_Czesc_1.pdf (access: 2020.10.19).

14. Długosz P. Research report: Cracow youth in quarantine conditions COVID-19. Inst. of Philosophy and Sociology, Pedagogical University KEN, Cracow; https://ifis.up.krakow.pl/wyniki-badan-laboratoriumsocjologicznego (access: 020.10.02).

15. Tabak I. Mental health of children and adolescents. Support for children and adolescents in overcoming problems. In: Health of Children and Adolescents. Selected Issues. Stud BAS. 2014; 2(38): 113-38.

16. Tian L, Zhao J, Huebner ES. School-related social support and subjective well-being in school among adolescents: The role of selfsystem factors. J Adolesc. 2015; 45: 138-48. https://doi.org/10.1016/j. adolescence.2015.09.003

17. Wypych-Ślusarska A, Głogowska-Ligus J, Słowiński J. Social determinants of health inequalities. Piel Zdr Publ. 2019; 9(3): 229-236. https://doi.org/10.17219/pzp/100468

18. Piróg D. In search of methodological innovations in qualitative research - example from the analysis of the transition of the graduates of geography to the labour market. Ann Univ Paedagog Cracoviensis Stud Geogr. 2014; 6: 9-18.

19. Kubinowski D. Qualitative pedagogical research. PhilosophyMethodology-Evaluation. Lublin: Publishing House of Maria CurieSkłodowska University; 2011.

20. Tariq S, Woodman J. Using mixed methods in health research. JRSM Short Reports. 2013; 4(6). https://doi. org/10.1177/2042533313479197

21. Remote education during the pandemic. Report from research. Digital Centre, Foundation, Warsaw; 2020. https://centrumcyfrowe. pl/edukacja-zdalna/\#English (access: 2020.10.02).

22. Remote education - where were we, where are we going? Preliminary results of scientific research: Remote education and adaptation to social conditions during the coronavirus epidemic. Research project, Remote learning; 2020. https://zdalnenauczanie.org/wp-content/ uploads/2020/06/Badanie-zdalnenauczanie_org_prezentacja.pdf. (access: 2020.10.01).

23. Ptaszek G, Bigaj M, Dębski M, Pyżalski J, Stunża GD. Remote educaction - where we were, where we are going? Preliminary results of the research: Remote learning and adaptation to social conditions during the coronavirus epidemic. Warsaw; 2020. p. 22-31. https://doi. org/10.13140/RG.2.2.25737.67685

24. Council on communications and media. Media Use in School-Aged Children and Adolescents. Pediatrics. 2016; 138(5). https://doi. org/10.1542/peds.2016-2592

25. Garza K, Jovanovic T. Impact of Gender on Child and Adolescent PTSD. Curr Psychiatry Rep. 2017; 19(11): 87. https://doi.org/10.1007/ s11920-017-0830-6

26. Małkowska-Szkutnik A. School environment. In: Students' health in 2018 against the backdrop of the new HBSC research model. Warsaw: Inst Mother and Child; 2018. p. 52.

27. Spinelli M, Lionetti F, Pastore M, Fasolo M. Parents' Stress and Children's Psychological Problems in Families Facing the COVID-19 Outbreak in Italy. Front. Psychol. 2020; 11: 1713. https://doi/10.3389/ fpsyg.2020.01713

28. Guessouma SB, Lachala J, Radjacka R, et al. Adolescent psychiatric disorders during the COVID-19 pandemic and lockdown. Psychiatry Res. 2020; 291: 113264; https://doi.org/10.1016/j.psychres.2020.113264 
29. Oblacińska A, Ostręga W. Standards of conduct and work methodology of a school nurse. A manual for school nurses and hygienists. Warsaw: Inst Mother and Child; 2017.

30. Darling-Hammond L, Cook-Harvey CM. Educating the whole child: Improving school climate to support student success. Learning Policy Inst. Palo Alto (CA); 2018. p. 27-32.

31. Blakemore SJ, Mills KL. Is adolescence a sensitive period for sociocultural processing? Annu Rev Psychol. 2014; 65: 187-207. https:// doi.org/10.1146/annurev-psych-010213-115202

32. Hawkley LC, Cacioppo JT. Loneliness matters: a theoretical and empirical review of consequences and mechanisms. Ann Behav Med. 2010; 40(2): 218-27. https://doi.org/10.1007/s12160-010-9210-8

33. Scott SR, Rivera KM, Rushing E. "I Hate This": A Qualitative Analysis of Adolescents' Self-Reported Challenges During the COVID-19 Pandemic. J Adolesc Health 2020; (Article in press; Online access 04.01.2021). https://doi.org/10.1016/j.jadohealth.2020.11.010

34. Jurczak A. The duality of teaching process during the coronavirus epidemic. J Inst Pre-School and Early School Education. 2020; VIII 1(15): 133-149.

35. Chrysanthos N. I never thought I'd say it, but I miss going to school. The Sydney Morning Herald.https://www.smh.com.au/national/nsw/inever-thought-i-d-say-it-but-i-miss-going-to-school-20200409-p54ik5. html (access: 2020.10.16).

36. Trends Shaping Education 2017 Spotlight. OECD (2016), Trends Shaping Education 2016, OECD Publishing (online) www.oecd.org/ edu/ceri (access: 31.12.2020).

37. Wilkin J. Polish countryside now and in the past - synthesis of the report. In: Wilkin J, Nurzyńska I, editors. Rural Poland 2018. The report on the state of rural areas. Warsaw: Wydawnictwo Naukowe
SCHOLAR; 2018. p. 11-24. https://www.fdpa.org.pl/rural-poland-2018 (access 31.12.2020).

38. Chmielewska B, Zegar JS. Rural convergence and divergence processes and the rest of society in terms of income. In: Wilkin J, Nurzyńska I, editors. Rural Poland 2018. The report on the state of rural areas. Warsaw: Scientific Publisher SCHOLAR; 2018. p. 111-134. https:// www.fdpa.org.pl/rural-poland-2018 (access 31.12.2020).

39. Hałaburda E. Family environmental determinants of learning results. Culture and Education $2020 \mathrm{nr} 1$; 127: 110-122. https://doi. org/10.15804/kie.2020.01.07

40. Becker SP, Breaux R, Cusick CN, et al. Remote Learning During COVID-19: Examining School Practices, Service Continuation, and Difficulties for Adolescents With and Without Attention-Deficit/ Hyperactivity Disorder. J Adolesc Health 2020; 67: 769-77. https:// doi.org/10.1016/j.jadohealth.2020.09.002

41. The Decree of the Minister of National Education on 12 August 2020 amending the decree on safety and hygiene in public and nonpublic schools and institutions. Act of 2020, Pub L No. 1386. https:// dziennikustaw.gov.pl/DU/2020/1386 (access: 2020.10.09).

42. Remote and hybrid learning for secondary school students - changes in the functioning of schools from Monday. Website of the Republic of Poland; Ministry of Education. https://www.gov.pl/web/edukacja/ nauka-zdalna-i-hybrydowa-w-szkolach-ponadpodstawowych. (access: 2020.10.16).

43. The Decree of the Minister of National Education on 23 October 2020 amending the decree on temporary limitation of the functioning of education units in connection with the prevention, counteraction and combating of COVID-19. Act of 2020, Pub L No. 1870. https:// www.dziennikustaw.gov.pl/D2020000187001.pdf (access: 2020 Oct 29). 